\title{
The shifting burden of neurosurgical disease: Vietnam and the middle-income nations
}

\author{
Christopher Carr, MD, MPH, ${ }^{1}$ Lora Kahn, MD, ${ }^{1}$ Mansour Mathkour, MD, MSc, MSCR, ${ }^{1}$ Erin Biro, MD, ${ }^{2}$ \\ Cuong J. Bui, MD, ${ }^{2}$ and Aaron S. Dumont, MD, MBA ${ }^{3}$
}

\begin{abstract}
${ }^{1}$ Tulane University-Ochsner Clinic Foundation Program, Department of Neurosurgery, Tulane University Medical Center; ${ }^{2}$ Department of Neurosurgery, Ochsner Health System; and ${ }^{3}$ Department of Neurosurgery, Tulane University Medical Center, New Orleans, Louisiana
\end{abstract}

\begin{abstract}
OBJECTIVE The Global Burden of Disease (GBD) is an international collaboration and the largest comprehensive investigation of global health disease burden ever conducted. It has been particularly insightful for understanding disease demographics in middle-income nations undergoing rapid development, such as Vietnam, where 6 of the top 10 causes of death are relevant to the neurosurgeon. The burden of stroke-the number one cause of death in Vietnam-is particularly impressive. Likewise, road injuries, with a disproportionate rate of traumatic brain injury, continue to increase in Vietnam following economic development. Low-back and neck pain is the number one cause of disability. Simultaneously, more patients have access to care, and healthcare spending is increased.
\end{abstract}

METHODS It is imperative that neurosurgical capital and infrastructure keep pace with Vietnam's growth. The authors searched the existing literature for assessments of neurosurgical infrastructure or initiatives to address neurosurgical disease burden. Using GBD data, the authors also abstracted data for death by cause and prevalence of years of life lost due to disability (YLD) for common neurosurgical pathologies for Vietnam and comparison nations.

RESULTS Interventions aimed at primary prevention of risk factors for neurosurgical disease and focused on the transference of self-sustainable technical skills were found to be analogous to those that have been successful in other regions. Efforts toward stroke prevention have been focused on causal risk factors. Multiple investigators have found that interventions aimed at increasing helmet use were successful in preventing traumatic brain injury. Government-led reforms and equipment donation programs have improved technical capacity. Nevertheless, Vietnam lags behind other nations in neurosurgeons per capita; cause-attributable death and YLD attributable to neurosurgical disease are considerably higher in Vietnam and middle-income nations compared to both lower-income nations and upper-income nations.

CONCLUSIONS More than two-thirds of deaths attributable to neurosurgical pathologies in Vietnam and other middleincome nations were due to stroke, and one-fifth of both cause-attributable death and YLD was associated with neurosurgical pathologies. Vietnam and other middle-income nations continue to assume a global burden of disease profile that ever more closely resembles that of developed nations, with particular cerebrovascular, neurotrauma, and spinal disease burdens, leading to exponentially increased demand for neurosurgeons that threatens to outpace the training of neurosurgeons.

https://thejns.org/doi/abs/10.3171/2018.7.FOCUS18297

KEYWORDS Vietnam; neurosurgery; Global Burden of Disease; stroke; traumatic brain injury; back pain

$\mathrm{T}$ HE Global Burden of Disease (GBD) is an international collaboration based at the University of Washington and funded through the Bill and Melinda Gates Foundation. It is the largest comprehensive investigation of global health disease burden ever conducted. The study began with the World Bank in 1990 and has been continued by the WHO. It currently involves more than 1800 researchers from more than 127 countries and con- tains standardized data that are systematically collected on 195 nations. The survey has been particularly insightful for understanding disease demographics in middle-income nations undergoing rapid development, such as Vietnam.

According to the GBD, the WHO, and the US Centers for Disease Control and Prevention, together with the Vietnamese government, Vietnam has a population of more than 94 million and a per capita gross domestic product (GDP)

ABBREVIATIONS COPD = chronic obstructive pulmonary disease; $\mathrm{DOHA}=$ Direction of Healthcare Activities; $\mathrm{GBD}=$ Global Burden of Disease; GDP = gross domestic product; $\mathrm{UI}=$ uncertainty interval; $\mathrm{YLD}=$ years of life lost due to disability.

SUBMITTED June 5, 2018. ACCEPTED July 16, 2018.

INCLUDE WHEN CITING DOI: 10.3171/2018.7.FOCUS18297. 
of about $\$ 6000$ US. Life expectancy is roughly 77 years for women and 70 years for men (http://www.healthdata.org/ vietnam; http://www.who.int/countries/vnm/en/). ${ }^{25}$ From 1990 to 2016, the proportion of total deaths in Vietnam due to communicable diseases decreased markedly as part of a greater trend over the past several decades throughout the developing world and particularly in middle-income nations (http://www.healthdata.org/vietnam). ${ }^{18}$

Accordingly, the top 8 leading causes of death in Vietnam in 2016 were "lifestyle diseases" (https://vizhub. healthdata.org/gbd-compare/; http://www.healthdata.org/ vietnam; Table 1). ${ }^{33}$ While such pathologies were once believed to be specific to the developed world, the GBD demonstrated that noncommunicable diseases are responsible for the majority of death and disability in middleincome nations. The top 10 causes of death in Vietnam were cerebrovascular disease, ischemic heart disease, Alzheimer disease (and other dementias), lung cancer, chronic obstructive pulmonary disease (COPD), diabetes, road injuries, chronic kidney disease, lower respiratory infection, and tuberculosis.

Of these 10 causes of death, 6 are of direct interest to the neurosurgeon, including ischemic heart disease, lung cancer, and tuberculosis; this interest is due to the propensity for thromboembolism, metastases, and CNS infection associated with these conditions. The burden of cerebrovascular disease-the number one cause of death in Vietnam-is particularly impressive: in 2010, stroke accounted for $11.2 \%$ of years of life lost in Vietnam, up from $6.6 \%$ in 1990. According to the 2017 Global Burden of Stroke report composed of GBD data, ${ }^{13}$ Vietnam has one of the highest proportional contributions to stroke-related death in the world. For instance, at $32 \%$, Vietnam trailed only Macedonia in the proportion of stroke-related death in women. Although progress has been made at reducing the burden of stroke adjusted for age, a longer-living population has resulted in a greater overall stroke burden. ${ }^{13}$

Likewise, road injuries continue to increase in Vietnam as economic development results in more vehicles on the road. Along with its neighbors Thailand and Indonesia, Vietnam is among the world leaders in road injuries. ${ }^{24} \mathrm{~A}$ high prevalence of motorized scooters has resulted in a disproportionate rate of traumatic brain injury following motor vehicle accidents (previously estimated at roughly $70 \%$ of all road injuries). ${ }^{19,21}$ As studies have shown superior outcomes with improved neurosurgical and neurocritical care, this compels additional investments in such neurosurgical capital. .11,28,39 $^{2}$

Similar to the rest of the world, low-back and neck pain is the number one cause of disability in Vietnam (http://www.healthdata.org/vietnam); its prevalence has increased 29.4\% since 2005. From 1990 to 2016, years of life lost due to disability (YLD) attributed to low-back and neck pain has increased from $9.71 \%$ of total YLDs to $12.14 \%$ (https://vizhub.healthdata.org/gbd-compare/). As such, the demand for spine surgeons is increasing. Thus, when death and disability metrics are combined, 3 of the top 4 pathologies in Vietnam are neurosurgical (cerebrovascular diseases, traumatic brain injuries, and spinal pathologies).

In addition to these pathologies, brain tumors and hy-
TABLE 1. Top 10 causes of death in Vietnam, with percentage change (2005-2016)

\begin{tabular}{rlrrc}
\hline \multirow{2}{*}{ Rank } & \multicolumn{1}{c}{ Cause } & Change & Percentage & \multicolumn{1}{c}{ Percentage } \\
& & +1.3 & 15.54 & 6.39 \\
\hline 1 & Stroke & +23.5 & 13.13 & 19.65 \\
\hline 2 & Ischemic heart disease & +41.4 & 6.42 & 8.62 \\
\hline 3 & Alzheimer disease & +35.1 & 5.95 & 6.91 \\
\hline 4 & Lung cancer & +15.9 & 4.35 & 5.91 \\
\hline 5 & COPD & +30.1 & 4.17 & 2.58 \\
\hline 6 & Diabetes & +8.5 & 3.67 & 1.61 \\
\hline 7 & Road injuries & +19.1 & 3.21 & 2.98 \\
\hline 8 & Chronic kidney disease & -5.9 & 2.83 & 3.46 \\
\hline 9 & Lower respiratory infection & -34.6 & 2.82 & 0.034 \\
\hline 10 & Tuberculosis &
\end{tabular}

The 2016 prevalence ratio between Vietnam and the US, calculated using the GBD data, was significantly greater than 1 for stroke, diabetes, road injuries, and tuberculosis.

* Relative proportion of deaths attributed to each disease in the US, for comparison.

drocephalus also carry a high burden of disease, particularly in poorer, nonurban communities, where delayed diagnosis is common due to lack of resources including quality imaging, cultural or religious barriers, and inadequate follow-up., , $, 26,27,40^{2}$

The literature has shown that disability-adjusted life years for all neurological disorders rose $37.6 \%$ from 1990 to 2015 , corresponding to an older population. ${ }^{16}$ At the same time, from 1990 to 2016, the Healthcare Access and Quality Index in Vietnam increased from 36.6 to 60.3 , meaning more patients had access to care, including care by neurosurgeons and other specialists (http://www. healthdata.org/vietnam) ${ }^{15}$ Healthcare spending is currently $\$ 390$ per capita (7.1\% of GDP), up nearly $2300 \%$ from $\$ 17$ per capita (approximately 4\% of GDP) in 1998 (http:// www.who.int/countries/vnm/en/). ${ }^{44}$

\section{Methods}

It is imperative that neurosurgical capital and infrastructure keep pace with Vietnam's growth. Accordingly, we searched the existing literature to determine if there have been any comprehensive assessments of neurosurgical infrastructure or public health initiatives to address neurosurgical disease burden. We were particularly interested in the specialties of cerebrovascular, neurotrauma, and spine.

We searched clinicaltrials.gov, the Cochrane Library, Embase, Google Scholar, PubMed, Web of Science, and the CINAHL (Cumulative Index to Nursing and Allied Health Literature) nursing database using the keywords "Vietnam and neurosurgery" and MeSH terms related to stroke and cerebrovascular disease, neurotrauma, and low-back and neck pain for articles pertaining to neurosurgical infrastructure changes in Vietnam or public health interventions to address stroke and cerebrovascular disease, road accidents, and low-back and neck pain. We also searched the professional economics literature using the 
JSTOR, EconLit, and World Development Indicators databases. Finally, we searched the bibliographies of all identified articles. Our most recent search was conducted on May 28, 2018. We acknowledge that the language restriction (English only) of the search and not having access to the body of Vietnamese medical literature and databases will give us an incomplete perspective into the country's neurosurgical infrastructure and public health initiatives.

Using the GBD data, we also abstracted data for death by cause and prevalence of YLD for common neurosurgical pathologies specifically for Vietnam. The pathologies chosen were meningoencephalitis, preterm birth, CNS cancer, stroke, Parkinson disease, epilepsy, low-back and neck pain, neural tube defects, and road injuries. For comparison purposes, we also included cause-attributable death and YLD data for the chosen neurosurgical diseases from representative nations close to World Bank GDP per capita quartile estimates for low income (Tanzania), middle income (China), and upper income (Japan, the US) (https://data.worldbank.org/indicator/NY.GDP. PCAP.CD?year_high_desc=false). Examination of several similar nations in each stratum showed a relative consistency in burden of neurosurgical disease as measured by YLD.

\section{Results}

Despite an exhaustive search, we did not find many articles in the English language literature specifically addressing neurosurgery in Vietnam. Nevertheless, the articles we did find appeared to confirm our hypothesis that it would be challenging for a highly specialized field such as neurosurgery to keep pace with Vietnam's rapid economic growth and the resultant disease burden shifts.

In 1997, Rosenfeld and Xuan wrote: ${ }^{38}$

\begin{abstract}
...the conditions of neurosurgery endured by our neurosurgical colleagues in Vietnam are far inferior to those in the developed world, particularly in terms of training, educational aids, investigative and operating room equipment, and postoperative and rehabilitative care. The recent formation of the Neurosurgical Society of Vietnam will help to improve these conditions, but help and encouragement from neurosurgeons in the developed world will also be of much value. The instigation of preventative strategies will likely make a significant impact on the health costs of neurotrauma in Vietnam.
\end{abstract}

The interventions we found enacted in the 20 years since tended to be ultra-low-cost and aimed at primary prevention of risk factors for neurosurgical disease or focused on the transference of self-sustainable technical skills from urban- to rural-based medical personnel. These interventions specific to Vietnam are analogous to those that have been successful in other regions. ${ }^{7,9,10}$

Among low-cost interventions aimed at primary prevention, efforts toward the primary prevention of stroke have been focused on diagnosis, prevention, and control of causal risk factors such as hypertension and diabetes, with systematic efforts led toward raising awareness of these conditions through media and toward decentralization of care into the countryside. Efforts aimed at decreasing smoking have been implemented through existing infrastructure, such as buses and schools. ${ }^{20,41}$ In terms of primary prevention of traumatic brain injury, multiple in-
TABLE 2. Comparison of population and number of neurosurgeons for Vietnam, the US, and Japan

\begin{tabular}{lccc}
\hline Nation & $\begin{array}{c}\text { Population } \\
\text { (millions) }\end{array}$ & $\begin{array}{c}\text { No. of } \\
\text { Neurosurgeons }\end{array}$ & $\begin{array}{c}\text { Neurosurgeons } \\
\text { per Capita }\end{array}$ \\
\hline Vietnam & 94 & 600 & 1 per 157,000 \\
\hline US & 328 & 3700 & 1 per 89,000 \\
\hline Japan & 126 & 7500 & 1 per 17,000 \\
\hline
\end{tabular}

Population estimates for Vietnam, the US, and Japan were obtained from https://www.cdc.gov/globalhealth/countries/vietnam/, https://www.census.gov/ popclock/, and https://www.cia.gov/library/publications/the-world-factbook/ geos/ja.html, respectively.

vestigators have found interventions aimed at increasing helmet use successful. ${ }^{19,32,36}$

Among practices aimed at improving advanced, technical capacity, the Direction of Healthcare Activities (DOHA) program has been developed over the past 50 years to accelerate the transfer of technical skills to community hospitals. While these reforms are considered anecdotally successful and have been described as a model for nations with limited healthcare resources, our search did not detect any reliable systematic assessment of the impact of DOHA activities..$^{43}$ There are some data to suggest that equipment donation programs can have a positive impact. ${ }^{45}$

As an example of how neurosurgical practice has changed in Vietnam in the 20 years since the original report by Rosenfeld and Xuan, Cho Ray Hospital in Ho Chi Minh City has reported a $46.2 \%$ increase in elective neurosurgical cases since 2004. ${ }^{27}$ This hospital has served as one of Vietnam's leading academic institutions. It has successfully leveraged cooperative programs with other nations ${ }^{42}$ Nevertheless, overall data are sparse, dominated by descriptive publications and qualitative reports; further efforts are needed to understand how the disproportionate burden of neurosurgical disease is being addressed in Vietnam and other middle-income nations. Additional quantitative analyses are necessary to provide higher-resolution success metrics.

As of 2018, there are more than 600 neurosurgeons in Vietnam, up from roughly 300 in 2008 . There are more than 10 universities and academic hospitals that graduate 50-60 surgeons per year (http://neurosurgery.vn/). Information about population and number of neurosurgeons for Vietnam, the US, and Japan is presented in Table 2. Additionally, we present the results of our GBD data analyses for cause-attributable death in Table 3 and YLD in Table 4. In terms of cause-attributable death, $21.16 \%$ (95\% uncertainty interval [UI] $19.18 \%-23.25 \%$ ) of deaths in Vietnam were attributable to neurosurgical pathology. These numbers were $10.92 \%$ (95\% UI 8.66\%-14.00\%), $23.29 \%$ (95\% UI $22.28 \%-24.24 \%), 10.78 \%$ (95\% UI $9.83 \%-$ $11.70 \%$ ), and $9.97 \%$ (95\% UI $9.41 \%-10.54 \%$ ) in Tanzania, China, Japan, and the US, respectively. In terms of YLD, neurosurgical pathologies accounted for $18.39 \%$ (95\% UI $14.85 \%-22.53 \%)$ of total YLD in Vietnam, $11.75 \%(95 \%$ UI 8.18\%-15.67\%) in Tanzania, 19.82\% (95\% UI 16.42\%$23.43 \%$ ) in China, $21.93 \%$ (95\% UI $18.55 \%-25.40 \%$ ) in Japan, and $16.94 \%$ (95\% UI $14.80 \%-19.20 \%$ ) in the US. 
TABLE 3. Death by cause for common neurosurgical pathologies in Tanzania, Vietnam, China, Japan, and the US, calculated using 2016 GBD data

\begin{tabular}{lccccc}
\hline \multicolumn{1}{c}{ Pathology } & Tanzania & Vietnam & China & Japan & US \\
\hline Meningoencephalitis & $2.40(1.77-3.50)$ & $0.40(0.32-0.54)$ & $0.11(0.081-0.15)$ & $0.072(0.062-0.097)$ & $0.081(0.071-0.11)$ \\
\hline Preterm birth & $2.28(1.56-3.19)$ & $0.56(0.39-0.77)$ & $0.29(0.25-0.32)$ & $0.016(0.014-0.018)$ & $0.25(0.24-0.27)$ \\
\hline Brain cancer & $0.20(0.17-0.25)$ & $0.21(0.17-0.24)$ & $0.61(0.55-0.69)$ & $0.19(0.15-0.21)$ & $0.61(0.53-0.64)$ \\
\hline Stroke & $3.77(3.23-4.33)$ & $15.54(14.52-16.61)$ & $18.52(17.94-19.08)$ & $9.08(8.4-9.72)$ & $6.39(6.05-6.73)$ \\
\hline Parkinson disease & $0.091(0.069-0.12)$ & $0.36(0.27-0.46)$ & $0.41(0.32-0.53)$ & $0.81(0.62-1.06)$ & $0.94(0.87-1.02)$ \\
\hline Epilepsy & $0.30(0.26-0.35)$ & $0.38(0.32-0.43)$ & $0.13(0.12-0.15)$ & $0.051(0.048-0.056)$ & $0.075(0.072-0.077)$ \\
\hline Low-back \& neck pain & 0 & 0 & 0 & 0 & 0 \\
\hline Neural tube defects & $0.15(0.071-0.30)$ & $0.037(0.016-0.072)$ & $0.0045(0.0037-0.0061)$ & $0.00093(0.00069-0.0012)$ & $0.016(0.014-0.018)$ \\
\hline Road injuries & $1.73(1.53-1.96)$ & $3.67(3.17-4.13)$ & $3.22(3.14-3.31)$ & $0.56(0.54-0.59)$ & $1.61(1.56-1.67)$ \\
\hline Total & $10.92(8.66-14.00)$ & $21.16(19.18-23.25)$ & $23.29(22.28-24.24)$ & $10.78(9.83-11.70)$ & $9.97(9.41-10.54)$ \\
\hline
\end{tabular}

All data given as percentages (95\% UI).

\section{Discussion}

In some ways, Vietnam is unique in terms of its impressive neurosurgical burden of disease: cerebrovascular disease is the leading cause of death in this nation of 94 million people, low-back and neck pain is the leading cause of disability, and neurotrauma from motor vehicle accidents is among the highest in the world despite effective intervention. ${ }^{23}$

Since 1976, Vietnam has been governed by a single-party government (The Socialist Republic of Vietnam), which already has the organizational infrastructure in place to enact centrally directed efforts to improve neurosurgical capacity and reduce disparities in care. Many economists would consider such a structure advantageous if healthcare delivery is a natural monopsony. ${ }^{6,34}$ While cerebrovascular disease has been the leading cause of death there since GBD statistics began in 1990, the absolute increase in stroke-related death since that time is due to a longerlived population. Indeed, age-adjusted stroke-related mortality has been declining, and improvements have also been made in neurotrauma metrics. These improvements follow public health interventions specifically designed to reduce the burden of stroke and increase helmet use.,20

In other ways, the changing burden of neurosurgical disease in Vietnam is quite typical of its category of rapidly modernizing, lower-middle-income nations with emerging economies and increasingly longer-lived populations susceptible to neurosurgical pathologies. Other developing nations with unusually high cerebrovascular disease and neurotrauma burdens include Vietnam's neighbors in Southeast Asia and Eastern European countries. Increasing wealth has led to noncommunicable diseases supplanting communicable diseases as leading causes of death and disability worldwide, although this trend is particularly profound in lower-middle-income and middle-income nations $;{ }^{17}$ this is compounded by an increased prevalence of preventable risk factors such as hypertension (which increased in Vietnam from < 1\% in 1960 to $>25 \%$ in 2010) and high rates of smoking ( $46 \%$ in Vietnam compared to $16 \%$ in the US) and alcohol consumption following increased access to wealth and global trade (http://www. who.int/gho/countries/vnm.pdf). . $^{8,1320,22,25,29,31}$ The overall effect has been a greater than $100 \%$ increase in stroke incidence in low- to middle-income nations worldwide since $1970 .{ }^{12}$ Likely stemming from poorly controlled hypertension, a disproportionate share of this stroke burden has been shown to be related to hemorrhagic stroke, a deadlier stroke subtype compared with ischemic stroke. ${ }^{2,14,37,46}$ While greater access to public health and primary care can ameliorate these risk factors, ${ }^{30}$ at the same time, there is increased demand for specialty care in treating acute conditions that can no longer be prevented.

Historically, wealthier nations have adopted a "barbell strategy" for public health, with simultaneous public investments in low-cost primary prevention and in highly technical specialty care. Developing nations such as Vietnam have likewise enacted policies incorporating both low-cost, primary prevention of neurosurgical diseases and transference of highly technical specialized skill sets. The emerging market economies are able to learn from the trial-and-error processes that many developed nations underwent to enact interventions that have been proven to be efficacious and cost-effective, such as blood pressure monitoring and helmet use..$^{35}$

In terms of the neurosurgical burden of disease and pathologies represented in Vietnam and comparison nations in our data analysis, middle-income nations (including Vietnam as a lower-middle-income nation and China as an upper-middle-income nation) had the highest overall burden of neurosurgical disease as measured by causeattributable death. In terms of YLD, these nations trailed only Japan, although this exception disappears when only cranial pathologies are examined. ${ }^{3}$ More than two-thirds of deaths attributable to neurosurgical pathologies in these middle-income nations were due to stroke; in comparison, death attributable to stroke was $35 \%$ of death attributable to neurosurgical causes in Tanzania, 84\% in Japan, and 64\% in the US. This relationship between national income and neurosurgical pathology, and the relationship between national income and stroke, in particular, are interesting findings that should be explored in more detail. Based on our analysis, we would hypothesize that an "inverse J curve" exists for the neurosurgical burden of disease worldwide, with middle-income nations having the highest burden. 
TABLE 4. Percentage of total YLD for common neurosurgical pathologies in Tanzania, Vietnam, China, Japan, and the US, calculated using 2016 GBD data

\begin{tabular}{llllll}
\hline \multicolumn{1}{c}{ Pathology } & \multicolumn{1}{c}{ Tanzania } & \multicolumn{1}{c}{ Vietnam } & \multicolumn{1}{c}{ China } & Japan & US \\
\hline Meningoencephalitis & $0.87(0.71-1.06)$ & $0.55(0.45-0.76)$ & $0.39(0.28-0.48)$ & $0.083(0.061-0.19)$ & $0.041(0.035-0.048)$ \\
\hline Preterm birth & $0.58(0.39-0.88)$ & $1.25(0.90-1.73)$ & $0.83(0.58-1.20)$ & $0.37(0.26-0.52)$ & $0.79(0.55-1.09)$ \\
\hline Brain cancer & $0.0044(0.0035-0.0055)$ & $0.0051(0.0039-0.0061)$ & $0.025(0.021-0.029)$ & $0.017(0.013-0.020)$ & $0.018(0.016-0.021)$ \\
\hline Stroke & $0.31(0.23-0.39)$ & $1.69(1.32-2.06)$ & $4.28(3.31-5.24)$ & $2.85(2.22-3.47)$ & $2.03(1.64-2.42)$ \\
\hline Parkinson disease & $0.018(0.013-0.025)$ & $0.085(0.063-0.11)$ & $0.12(0.089-0.16)$ & $0.17(0.13-0.23)$ & $0.19(0.16-0.22)$ \\
\hline Epilepsy & $1.9(0.43-3.82)$ & $1.31(0.41-2.45)$ & $0.72(0.51-0.96)$ & $0.33(0.23-0.46)$ & $0.69(0.48-0.93)$ \\
\hline Low-back \& neck pain & $7.03(5.86-8.20)$ & $12.14(10.63-13.72)$ & $11.63(10.17-13.13)$ & $16.69(14.52-18.75)$ & $11.72(10.77-12.65)$ \\
\hline Neural tube defects & $0.39(0.30-0.48)$ & $0.12(0.092-0.14)$ & $0.10(0.084-0.12)$ & $0.11(0.09-0.13)$ & $0.11(0.093-0.13)$ \\
\hline Road injuries & $0.65(0.51-0.81)$ & $1.24(0.98-1.55)$ & $1.72(1.38-2.11)$ & $1.31(1.03-1.63$ & $1.35(1.06-1.69)$ \\
\hline Total & $11.75(8.18-15.67)$ & $18.39(14.85-22.53)$ & $19.82(16.42-23.43)$ & $21.93(18.55-25.40)$ & $16.94(14.80-19.20)$ \\
\hline
\end{tabular}

All data given as percentages $(95 \% \mathrm{UI})$.

While back pain was proportionally the largest neurosurgical pathology contributing to YLD, ratios were similar across nations, suggesting that back pain plagues the rich and poor alike. Finally, one-fifth of both cause-attributable death and YLD was associated with neurosurgical pathologies in both Vietnam and China. This is a large number that compels neurosurgical and public health intervention to address the causes and effects of these diseases.

As part of the resident training curriculum, our chief resident and several attendings spend time annually at several major hospitals in Vietnam. Through an exchange, Vietnamese bác sĩ (doctors) reciprocally also spend educational time in the US. The neurosurgical teams maintain e-mail communication throughout the year to discuss difficult cases and exchange neurosurgical ideas; this experience has given us some anecdotal support for the data discussed here.

\section{Conclusions}

Vietnam and other middle-income nations continue to assume a global burden of disease profile that ever more closely resembles that of developed nations, with particular cerebrovascular, neurotrauma, and spinal disease burdens. This has led to exponentially increased demand for neurosurgeons worldwide. Efforts at addressing these shifting disease demographics have benefitted from the existing public health literature and have focused largely on both primary prevention and dissemination of advanced technical knowledge and equipment. Further efforts are needed to better characterize and address this shifting disease burden in the developing world, including international partnerships similar to GBD but with neurosurgical focus. Middle-income nations appear to be especially plagued by increases in neurosurgical pathology that are outpacing the training of neurosurgeons.

\section{References}

1. AIP Foundation: Head First: a case study of Vietnam's motorcycle helmet. Issuu. December 14, 2017. (https://issuu. com/aipfoundation/docs/aipf-10-year-helmet-law-report-fina) [Accessed August 8, 2018]
2. Andersen KK, Olsen TS, Dehlendorff C, Kammersgaard LP: Hemorrhagic and ischemic strokes compared: stroke severity, mortality, and risk factors. Stroke 40:2068-2072, 2009

3. Asamoto S: Neurosurgeons in Japan are exclusively brain surgeons. World Neurosurg 99:145-149, 2017

4. Bean JR: International neurosurgical care: attending to those in need. World Neurosurg 112:322-324, 2018

5. Bramall A, Djimbaye H, Tolessa C, Biluts H, Abebe M, Bernstein M: Attitudes toward neurosurgery in a low-income country: a qualitative study. World Neurosurg 82:560-566, 2014

6. Broomberg J: Managing the health care market in developing countries: prospects and problems. Health Policy Plan 9:237-251, 1994

7. Budohoski KP, Ngerageza JG, Austard B, Fuller A, Galler R, Haglund M, et al: Neurosurgery in East Africa: innovations. World Neurosurg 113:436-452, 2018

8. Centers for Disease Control and Prevention: Smoking and tobacco use-current cigarette smoking among adults in the United States. CDC.gov. (https://www.cdc.gov/tobacco/ data_statistics/fact_sheets/adult_data/cig_smoking/index. htm) [Accessed August 8, 2018]

9. Dempsey KE, Qureshi MM, Ondoma SM, Dempsey RJ: Effect of geopolitical forces on neurosurgical training in SubSaharan Africa. World Neurosurg 101:196-202, 2017

10. Dempsey R, Nakaji P: Foundation for International Education in Neurological Surgery (FIENS) global health and neurosurgical volunteerism. Neurosurgery 73:1070-1071, 2013

11. Egawa S, Hifumi T, Kawakita K, Okauchi M, Shindo A, Kawanishi M, et al: Impact of neurointensivist-managed intensive care unit implementation on patient outcomes after aneurysmal subarachnoid hemorrhage. J Crit Care 32:5255,2016

12. Feigin VL, Lawes CM, Bennett DA, Barker-Collo SL, Parag $\mathrm{V}$ : Worldwide stroke incidence and early case fatality reported in 56 population-based studies: a systematic review. Lancet Neurol 8:355-369, 2009

13. Feigin VL, Norrving B, Mensah GA: Global burden of stroke. Circ Res 120:439-448, 2017

14. Garbusinski JM, van der Sande MA, Bartholome EJ, Dramaix M, Gaye A, Coleman R, et al: Stroke presentation and outcome in developing countries: a prospective study in the Gambia. Stroke 36:1388-1393, 2005

15. GBD 2015 Healthcare Access and Quality Collaborators: Healthcare Access and Quality Index based on mortality from causes amenable to personal health care in 195 countries and territories, 1990-2015: a novel analysis from the Global Burden of Disease Study 2015. Lancet 390:231-266, 2017 
16. GBD 2015 Neurological Disorders Collaborator Group: Global, regional, and national burden of neurological disorders during 1990-2015: a systematic analysis for the Global Burden of Disease Study 2015. Lancet Neurol 16:877-897, 2017

17. GBD 2016 DALYs and HALE Collaborators: Global, regional, and national disability-adjusted life-years (DALYs) for 333 diseases and injuries and healthy life expectancy (HALE) for 195 countries and territories, 1990-2016: a systematic analysis for the Global Burden of Disease Study 2016. Lancet 390:1260-1344, 2017

18. Institute for Health Metrics and Evaluation: Global Burden of Diseases, Injuries, and Risk Factors Study 2010. GBD profile: Vietnam. HealthData.org. (http://www.healthdata.org/sites/ default/files/files/country_profiles/GBD/ihme_gbd_country_ report_vietnam.pdf) [Accessed August 8, 2018]

19. Ha NT, Ederer D, Vo VAH, Pham AV, Mounts A, Nolen LD, et al: Changes in motorcycle-related injuries and deaths after mandatory motorcycle helmet law in a district of Vietnam. Traffic Inj Prev 19:75-80, 2018

20. Harper C: Vietnam Noncommunicable Disease Prevention and Control Programme 2002-2010: Implementation Review. Geneva: World Health Organization, 2011

21. Hoang HT, Pham TL, Vo TT, Nguyen PK, Doran CM, Hill PS: The costs of traumatic brain injury due to motorcycle accidents in Hanoi, Vietnam. Cost Eff Resour Alloc 6:17, 2008

22. Hoang Anh PT, Thu T, Ross H, Quynh Anh N, Linh BN, Minh NT: Direct and indirect costs of smoking in Vietnam. Tob Control 25:96-100, 2016

23. Hung DV, Stevenson MR, Ivers RQ. Prevalence of helmet use among motorcycle rider in Vietnam. Inj Prev 12:409-413, 2016

24. Institute for Health Metrics and Evaluation: The Global Burden of Disease: Generating Evidence, Guiding Policy-East Asia and Pacific Regional Edition. Seattle: Institute for Health Metrics and Evaluation, 2013. (http:// www.healthdata.org/policy-report/global-burden-diseasegenerating-evidence-guiding-policy---east-asia-and-pacific) [Accessed August 9, 2018]

25. Johnston SC, Mendis S, Mathers CD: Global variation in stroke burden and mortality: estimates from monitoring, surveillance, and modelling. Lancet Neurol 8:345-354, 2009

26. Kaptigau WM, Rosenfeld JV, Kevau I, Watters DA: The establishment and development of neurosurgery services in Papua New Guinea. World J Surg 40:251-257, 2016

27. Karras CL, Tran HM, Dornbos D III, Nguyen P, Nimjee SM, Prevedello DM, et al: Inside Vietnam's largest neurosurgery department. World Neurosurg 105:122-125, 2017

28. Knopf L, Staff I, Gomes J, McCullough L: Impact of a neurointensivist on outcomes in critically ill stroke patients. Neurocrit Care 16:63-71, 2012

29. Lê VT, Lê TL, Nguyên TH, Nguyên HH, Dào TX, Nguyên VT, et al: [Strokes in South Vietnam: an epidemiologic study.] Rev Neurol (Paris) 155:137-140, 1999 (Fr)

30. Lim J, Chan MMH, Alsagoff FZ, Ha D: Innovations in noncommunicable diseases management in ASEAN: a case series. Glob Health Action 7:25110, 2014

31. Murray CJ, Vos T, Lozano R, Naghavi M, Flaxman AD, Michaud C, et al: Disability-adjusted life years (DALYs) for 291 diseases and injuries in 21 regions, 1990-2010: a systematic analysis for the Global Burden of Disease Study 2010. Lancet 380:2197-2223, 2012 (Erratum in Lancet 381:628, 2013)

32. Nguyen HT, Passmore J, Cuong PV, Nguyen NP: Measuring compliance with Viet Nam's mandatory motorcycle helmet legislation. Int J Inj Contr Saf Promot 20:192-196, 2013

33. Nhung NT, Long TK, Linh BN, Vos T, Huong NT, Anh ND: Estimation of Vietnam national burden of disease 2008. Asia Pac J Public Health 26:527-535, 2014

34. Pauly MV: Managed care, market power, and monopsony. Health Serv Res 33:1439-1460, 1998
35. Peden M, Scurfield R, Sleet D, Mohan D, Hyder AA, Jarawan E, et al: World Report on Road Traffic Injury Prevention. Geneva: World Health Organization, 2004. (http://www.who. int/violence_injury_prevention/publications/road_traffic/ world_report/en/) [Accessed August 9, 2018]

36. Pervin A, Passmore J, Sidik M, McKinley T, Nguyen TH, Nguyen PN: Viet Nam's mandatory motorcycle helmet law and its impact on children. Bull World Health Organ 87:369-373, 2009

37. Poungvarin N: Stroke in the developing world. Lancet 352 (Suppl 3):SIII19-SIII22, 1998

38. Rosenfeld JV, Xuan NT: Neurosurgery in Vietnam. Surg Neurol 48:307-311, 1997

39. Sekhon MS, Gooderham P, Toyota B, Kherzi N, Hu V, Dhingra VK, et al: Implementation of neurocritical care is associated with improved outcomes in traumatic brain injury. Can J Neurol Sci 44:350-357, 2017

40. Servadei F, Rossini Z, Nicolosi F, Morselli C, Park KB: The role of neurosurgery in countries with limited facilities: facts and challenges. World Neurosurg 112:315-321, 2018

41. Son PT, Quang NN, Viet NL, Khai PG, Wall S, Weinehall L, et al: Prevalence, awareness, treatment and control of hypertension in Vietnam - results from a national survey. J Hum Hypertens 26:268-280, 2012

42. Sugimori H, Hiramatsu Y, Sakakibara Y: [Cooperation between the Department of Cardiovascular Surgery in University of Tsukuba and Cho-Ray Hospital, Ho-Chi-Minh City, Vietnam-for an attractive collaboration in international medical education.] Nippon Geka Gakkai Zasshi 113:252256, 2012 (Jpn)

43. Takashima K, Wada K, Tra TT, Smith DR: A review of Vietnam's healthcare reform through the Direction of Healthcare Activities (DOHA). Environ Health Prev Med 22:74, 2017

44. Tien TV, Phuong HT, Mathauer I, Phuong NTK: A Health Financing Review of Viet Nam with a Focus on Social Health Insurance-Bottlenecks in Institutional Design and Organizational Practice of Health Financing and Options to Accelerate Progress towards Universal Coverage. Geneva: World Health Organization, 2011

45. Venturini S, Park KB: Evaluating the effectiveness and the impact of donated neurosurgical equipment on neurosurgical units in low- and middle-income countries: the World Federation of Neurosurgical Societies Experience. World Neurosurg 109:98-109, 2018

46. Yamanashi H, Ngoc MQ, Huy TV, Suzuki M, Tsujino A, Toizumi M, et al: Population-based incidence rates of first-ever stroke in Central Vietnam. PLoS One 11:e0160665, 2016

\section{Disclosures}

The authors report no conflict of interest concerning the materials or methods used in this study or the findings specified in this paper.

\section{Author Contributions}

Conception and design: Carr, Mathkour, Dumont. Acquisition of data: Carr, Kahn, Biro, Bui. Analysis and interpretation of data: Carr. Drafting the article: Carr. Critically revising the article: Kahn, Mathkour, Biro, Bui, Dumont. Reviewed submitted version of manuscript: all authors. Statistical analysis: Carr. Administrative/technical/material support: Kahn, Mathkour, Biro, Bui, Dumont. Study supervision: Biro, Bui, Dumont.

\section{Correspondence}

Christopher Carr: Tulane Medical Center, New Orleans, LA. ccarr6@tulane.edu. 